\title{
Operating Modes of the Advanced Purification Technology for Graphite Application in Lithium-Ion Batteries
}

\author{
$\underline{\text { Serhii Fedorov }}^{1}$, Artem Sybir $^{1}$, Simon Hubinskyi $^{2}$, Lina Kieush $^{1}$, Andrii Koveria $^{1}$
}

1. Department of Industrial Heat Engineering, National Metallurgical Academy of Ukraine, UKRAINE, Dnipro, 4\# Gagarina Avenue, E-mail: fedorov.pte@gmail.com

2. Department of Research and Development, Thermal and Material Engineering Center, UKRAINE, Dnipro, 2a\# Dmitra Yavornitskoho Avenue, E-mail: info@tmec.com.ua

Abstract - The subject of the study is the influence of the ash content in Ukrainian natural graphite on treatment duration in thermal refining natural graphite to battery grade. At temperatures 2900$3000^{\circ} \mathrm{C}$, the required purity can be achieved in 5-15 minutes regardless initial level of impurities.

Keywords - lithium-ion batteries, natural graphite, thermal purification, operating modes.

\section{Introduction}

Within the next five years, it is expected a huge expansion of the batteries graphite global market due to the growing demand for electric vehicles and electric storage stations. The major challenge related to this development is there are a few scalable technologies, in particular thermal [1] and chemical [2] treatment, applicable in industry that can potentially meet all market requirements such as product output and purity. However, it is supposed only the thermal process has respective capability to produce so-called "green" purified graphite of 99,95-99,98\% carbon grade in environmentally friendly way with low carbon dioxide footprint. That can be achieved by wide application of renewables at different stages of the technology as well as heat waste recovery from final product.

In this connection, for more than ten years, National Metallurgical Academy (NMAU) along with Thermal and Material Engineering Center (TMEC) has been working on the advanced thermal purification technology based on electro-thermal fluidized bed (ETFBP) with specific focus on product quality, energy consumption rate and environmental impact to surpass existing analogues.

\section{Objectives of Study}

The duration of graphite treatment via ETFBP defines the furnace productivity and depends on different factors like initial amount of impurities in precursor material, particle size, operating temperature and required product purity. Therefore, the main objective of the current study is to figure out whether there are perceptible time limits for purification of natural graphite with various initial ash content in range $0,4-27 \%$ at temperatures $2900-3000^{\circ} \mathrm{C}$.

\section{Research Method}

For this purpose, a laboratory furnace of $5 \mathrm{~kW}$ power was developed, Fig. 1. The furnace consists of a crucible, resistive heater, thermal insulation, inert gas and electric supply systems. The size of the operating space ensures up to $50 \mathrm{~g}$ payload of carbon material for treatment at temperatures $1000-3000^{\circ} \mathrm{C}$.

In small reactors like this one with harsh inner environment, the issue of temperature measurement methods is crucial. Thermo-couple sensors do not fit for this purpose and can be installed only in isulation. Thus, they would not transmit accurate data on real state of a sample. On the other hand, heat losses do not allow to apply pyrometers, because that affects inside temperatures. Therefore, our team decided to control the regime in accordance to an operating 
curve which ties the temperature value with the electric current passing through the resistive heater.

The operating curve was built on the basis of preliminary study of the behaviour of various control-samples ('witnesses') during heating them and soaking at set electric parameters. The samples were made of copper, stainless steel, corundum ceramic and some carbides - materials with known melting point. According to our evaluations this solution secured measurement accuracy in range $\pm 75^{\circ} \mathrm{C}$ that is comparable to pyrometers performance.

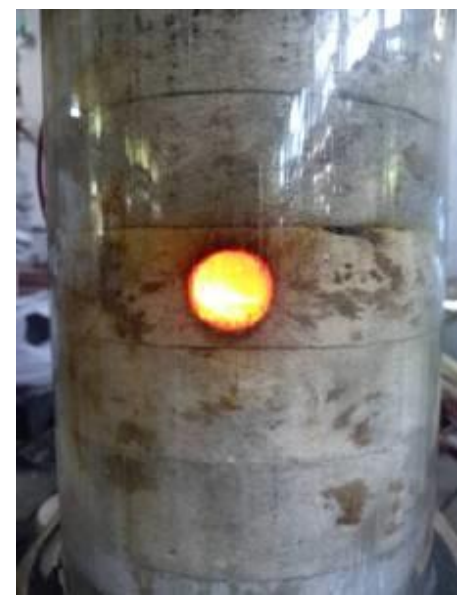

Fig.1. The laboratory reactor for thermal purification.

As a gaseous inert agent, Argon was used. Before every purification cycle the furnace was blown with a small Argon flow, approximately $1 \mathrm{~L} / \mathrm{min}$, for 5 minutes and sequentially heated up at $0,8-1,2 \mathrm{~kW}$ power for 10 minutes, that was enough for replacement of air and water evaporation from the inner parts. Further, according to the operating curve, the electric power was being increased up to $3,6-4,5 \mathrm{~kW}$ to maintain set temperatures level for time period from 5 to 20 minutes.

Purified samples was being weighed and tested on physical and chemical properties. To evaluate graphite quality, there were also used the microscope Tescan Mira 3 LMU, detector Oxford X-max 80, conventional 'lost on ignition' test and laboratory method for measurement of graphite electric resistivity.

\section{Results and Discussion}

The considerable achievement of the completed work is the furnace, which has been designed and developed by our team, has demonstrated outstanding performance with sufficient withstanding of high temperatures and impact of various chemical impurities on the crucible, thermal insulation and resistive heater. The duration of purification cycle including blowing, heating, soaking and cooling has been decreased to 30-40 minutes that provide us the possibility to conduct multiple experiments, up to 8-10, during one shift.

According to the experimental data, at temperatures $2000-3000^{\circ} \mathrm{C}$, impurities volatilization occurs with high rate of reaction. That has been also proven by visual observation - the 'cold' furnace elements made of quartz glass were changing their transparency promptly within 30-60 seconds.

The typical results are presented in Table 1. The sufficient graphite purity of $99,99 \%$ has been secured at temperature level $>2900^{\circ} \mathrm{C}$ equally for all samples of initial ash content 0,4$27 \%$. The time limitations of the purification process are mainly related to the heating-up rate of the inner layers of samples. In samples of small weight from 5 to $10 \mathrm{~g}$, the graphite can be 
purified within 5 minutes. There was a regularity in the study that should be also mentioned. The traces of $\mathrm{Ca}, \mathrm{Fe}$ and $\mathrm{Ti}$ are present in the product relatively at considerable amount.

Therefore, the study has proved capabilities of high thermal purification of natural graphite in 5-15 minutes. The results will be used for justification of operating modes of ETFBP technology for Ukrainian raw materials. The developed experimental approach is to be used for other carbon materials like biochar, metallurgical and petroleum coke, carbon black, brown and hard coal, anthracite with focus of their further application in various industrial processes.

Table 1

Impurities content after thermal purification of natural graphite from the Ukrainian mine

\begin{tabular}{|c|c|c|c|}
\hline Type of impurities & Precursor material & Purified material & Units \\
\hline Total Ash & 10.58 & $<0.01$ & $\%$ \\
\hline $\mathrm{Al}$ & 7337.2 & - & $\mathrm{ppm}$ \\
\hline $\mathrm{Si}$ & 18134.1 & $<2.8$ & $\mathrm{ppm}$ \\
\hline $\mathrm{S}$ & 1082.3 & - & $\mathrm{ppm}$ \\
\hline $\mathrm{K}$ & 2072.6 & - & $\mathrm{ppm}$ \\
\hline $\mathrm{Ca}$ & 1917.1 & $<11.1$ & $\mathrm{ppm}$ \\
\hline $\mathrm{Ti}$ & 453.9 & $<15.5$ & $\mathrm{ppm}$ \\
\hline $\mathrm{V}$ & 94.2 & $<2.2$ & $\mathrm{ppm}$ \\
\hline $\mathrm{Mn}$ & 280.4 & - & $\mathrm{ppm}$ \\
\hline $\mathrm{Fe}$ & 29377.5 & $<27.5$ & $\mathrm{ppm}$ \\
\hline $\mathrm{Cu}$ & 351.3 & - & $\mathrm{ppm}$ \\
\hline $\mathrm{Zn}$ & 561.8 & $<1.2$ & $\mathrm{ppm}$ \\
\hline $\mathrm{Mo}$ & 84.6 & $<4.3$ & $\mathrm{ppm}$ \\
\hline
\end{tabular}

Conclusion

The laboratory furnace of $5 \mathrm{~kW}$ power for graphite purification is developed and tested.

The subject of the study is the influence of the ash content in Ukrainian natural graphite on treatment duration in thermal refining the material to battery grade. At temperatures 2900$3000^{\circ} \mathrm{C}$, the graphite grade of $99,99 \%$ can be achieved in 5-15 minutes regardless initial level of impurities. The results prove efficiency of the ETFBP technology and can be used for its adjustment for Ukrainian graphite,

\section{Acknowledgments}

Authors would like to acknowledge scientific contributions by Professor Michailo Hubinskyi, Head of Department of Industrial Heat Engineering at NMAU, who took part in this research.

\section{References}

[1] Fedorov, S. S., Rohatgi, U. S., Barsukov, I. V., Gubynskyi, M. V., Barsukov, M. G., Wells, B. S., Livitan, M. V., Gogotsi, O. G. (2015). Ultrahigh-Temperature Continuous Reactors Based on Electrothermal Fluidized Bed Concept. Journal of Fluids Engineering, 138(4), 044502. doi:10.1115/1.4031689.

[2] Fedorov, S. S. (Au.), Hubynskyi, S. M. (Ed.) (2018, October 20). Thermal Purification of Carbon Materials. Retrieved February 22, 2019, from https://tmec.com.ua/en/menu/thermal-purification-ofcarbon-materials?_url=/menu/thermalpurification-of-carbon-materials 